\title{
A OBRA DE GEORGES SNYDERS NO CENÁRIO EDUCACIONAL BRASILEIRO: INTRODUÇÃO, APROPRIAÇÕES E REFLUXO
}

\author{
Renata de Almeida Vieira ${ }^{1}$
}

\begin{abstract}
RESUMO
O objetivo deste artigo, o qual corresponde a um recorte de uma pesquisa ${ }^{2}$ mais ampla, é dimensionar a influência, no Brasil, do educador francês Georges Snyders. Para tanto, apresenta-se o resultado de uma pesquisa bibliográfica de caráter descritivo e interpretativo. Com o fito de explicitar como esse educador marxista tornou-se conhecido por aqui, aborda-se a respeito da introdução e repercussão de seu pensamento pedagógico no cenário educacional brasileiro, pensamento este que se constituiu em uma das referências basilares da Pedagogia Histórico-Crítica. São abordadas, ainda, as referências e apropriações de suas ideias e obras por autores brasileiros, bem como se apresenta um quadro atualizado do conjunto de seus livros e se discute acerca do refluxo da publicação de suas obras em língua portuguesa. Com base no resultado da pesquisa empreendida, sinaliza-se para a importância de estudos a respeito da obra snyderiana, uma vez que sua concepção pedagógica crítica e dialética tem potencial para promover uma compreensão atualizada de questões educacionais e escolares emergentes.

Palavras-chave: Georges Snyders; Pedagogia Histórico-Crítica; Educação.
\end{abstract}

\section{GEORGES SNYDERS' WORK ON THE BRAZILIAN EDUCATIONAL SCENARIO: INTRODUCTION, APPROPRIATIONS AND REFLUX}

\begin{abstract}
The aim of this article, which corresponds to part of a more comprehensive research, is to dimension the influence of the French educator Georges Snyders in Brazil. To reach such intent, we present the results of a literature review with descriptive and interpretative nature. With the aim of explaining how this Marxist educator became known here, the introduction and impact of his pedagogical thinking on the Brazilian educational scenario is approached once his thought became one of the cornerstones of the Historical-Critical Pedagogy. References and appropriations of his ideas and works by Brazilian authors are addressed as well as an updated picture of his books. The publication reflux of his works in Portuguese is also discussed. Based on the results of the present work, we highlight the importance of studying about George Snyders' works as his pedagogical, critical, and dialectical conceptions have the potential to promote the understanding of current educational and school emerging issues.

Keywords: Georges Snyders; Historical-Critical Pedagogy; Education.
\end{abstract}

\section{Introdução}

Temos observado, atualmente, uma crescente corrosão da especificidade formativa que tem lugar na instituição escolar. Ao ter sua especificidade diluída, tal instituição tem assumido funções que não correspondem, necessariamente, ao ensinar e aprender conteúdos culturais enriquecedores da humanidade dos sujeitos que a constituem. É possível perceber que, concomitante à hipertrofia de discursos ideológicos que estão comprometidos com a conservação do status quo escolar e social e que chegam, até 
mesmo, a rotular de preconceituoso e autoritário o professor que ensina conteúdos culturais sistematizados e mais complexos, há um preocupante esvaziamento da atividade docente, dos vínculos pedagógicos entre professores e alunos, dos conteúdos de ensino e de aprendizagem, entre outros aspectos referentes ao universo escolar (DUARTE, 2001b).

Nesse contexto, torna-se um exercício de ousadia o posicionamento a favor de um ideário educacional que tenha como princípio maior ensinar conteúdos mais elaborados, de modo diretivo e com intencionalidade explícita, em que professor e aluno tenham papéis definidos, em que o esforço conjunto esteja presente no espaço-tempo de aprendizagem e de ensino. Torna-se ousadia justamente porque, em nossa época, tem ganhado vulto um discurso de descrédito da existência de verdade e de referentes (MORAES, 2001), o que provoca, por conseguinte, um descrédito em relação ao próprio ensino às gerações mais novas das produções consideradas patrimônio científico, filosófico, artístico, enfim, cultural da humanidade. Estas e outras questões emergentes em nosso contexto educacional têm nos chamado a atenção.

No afã de entender a significação das mesmas, consideramos necessária a busca por fundamentação teórica que nos permita pensá-las não só por aquilo que são como pela sua dimensão contrária. Pressupomos que pensá-las contrariamente somente seja possível quando concebemos a educação sob uma perspectiva crítica e historicizada, posicionandonos afirmativamente em relação à função da escola na promoção do desenvolvimento dos escolares por meio da apropriação das produções humanas mais elaboradas (DUARTE, 2001a, 2001b, 2003).

Priorizar estudos que caminham nessa direção, tal como os de autoria de Georges Snyders (1917-2011), consiste, em nosso entendimento, condição sine qua non para nos posicionarmos contrários aos processos em curso e afirmarmos a especificidade da educação escolar no que toca ao ensinar e aprender conteúdos mais complexos e não cotidianos.

Com base nesse entendimento e no intuito de contribuir para a divulgação da obra pedagógica do educador francês Georges Snyders, apresentamos, neste artigo, que se trata de um recorte de uma pesquisa mais ampla, um estudo sobre a introdução, apropriações e refluxo de sua obra no cenário educacional brasileiro.

\section{Introdução do pensamento pedagógico de Georges Snyders no Brasil}

A introdução do pensamento educacional de Georges Snyders no cenário brasileiro teve início a partir de meados da década de 70 do século XX.

Encontramos pistas a respeito do marco inicial de entrada de suas obras em território nacional em um texto escrito por Dermeval Saviani por ocasião da abertura de um evento em Goiânia no ano de 1988, promovido pelo Programa de Pós-Graduação em Educação da Universidade Federal de Goiás, cujo convidado principal foi Georges Snyders.

Nesse texto, que dá as boas-vindas ao professor Georges Snyders em sua primeira visita ao Brasil, Saviani (1988, p. 5) destaca a disseminação de seu pensamento: “[...] em que pese ser a sua primeira visita ao nosso país, ele já se encontra entre nós, por meio de seus livros, desde pelo menos 1976". Além disso, procura relembrá-lo do primeiro contato que manteve com ele na década de 1970:

O professor talvez não se lembre, mas quando o visitei em Paris, em 1977, fui agraciado por ele próprio com a tradução portuguesa de seus livros 'Où vont les pédagogies non directives' e 'École, classe et lutte des classes'. Entretanto, antes mesmo de conhecer as traduções portuguesas 
vinha já utilizando suas obras nos cursos por mim ministrados. E desde essa época seus livros 'Pedagogia Progressista', 'Para onde vão as Pedagogias Não-Diretivas' e 'Escola, classe e luta de classes' constituem leituras obrigatórias na disciplina Filosofia da Educação que eu vinha lecionando todos os anos na PUC de São Paulo (SAVIANI, 1988, p. 5).

Os destaques realizados por Saviani (1988) mostram os primeiros contatos de educadores brasileiros com a obra de Georges Snyders. Evidenciam, ademais, se observarmos as datas de publicação das obras citadas - 1971, 1973 e 1976 respectivamente -, que, rapidamente, após lançadas na França, as mesmas já estavam circulando e sendo estudadas por aqui.

Tal contato com as obras do educador francês teve lugar em um contexto de busca por referências que contribuíssem para uma análise crítica da educação brasileira ante suas mazelas e sob o controle do Regime Militar. Carvalho (1996, p. 5), em sua dissertação de mestrado, expõe o seguinte:

Em busca de novas referências teórico-metodológicas para o ensino no Brasil, procurando sair da esfera do liberalismo (do pensamento liberal/burguês) e das propostas de educação por ele engendradas, alguns pesquisadores e teóricos, vão buscar, principalmente na Europa, novos referenciais apoiados no marxismo ou na reformulação mais profunda do próprio liberalismo.

Constatamos que o contato de educadores brasileiros com o pensamento snyderiano foi frutuoso, haja vista que o mesmo tornou-se, no Brasil, uma das referências basilares da pedagogia histórico-crítica. Saviani (1988, p. 6), assim expressa essa influência:

Snyders é, [...] uma das referências fundamentais da corrente pedagógica que venho chamando de 'pedagogia histórico-crítica', uma pedagogia enraizada na História e que, inspirada no marxismo, pretende ser a síntese superadora tanto das pedagogias tradicional e nova como das teorias crítico-reprodutivistas. [...] mesma síntese que Snyders persegue constante e competentemente em todas as suas obras.

Acerca da corrente pedagógica mencionada, qual seja, a pedagogia histórico-crítica, cuja influência de Georges Snyders, em sua constituição, é publicamente reconhecida pelo professor Saviani (1988) nessa apresentação, fica evidente que se trata de uma perspectiva crítica no âmbito da pedagogia no Brasil. Na condição de principal expoente teórico dessa corrente pedagógica, Saviani (2003b) indica, na introdução do livro Pedagogia históricocrítica: primeiras aproximações, o ano de 1979 como um marco da configuração da concepção histórico-crítica e demarca como motivo crucial para sua edificação o início da discussão mais ampla e coletiva do problema de se abordar dialeticamente a educação.

Uma introdução preliminar à pedagogia histórico-crítica é encontrada no livro Escola e democracia (SAVIANI, 2003a), constituído por quatro textos escritos entre os anos de 1981 e 1983. A designação de histórico-crítica, segundo seu autor, passou a ser adotada a partir de 1984 e, na condição de corrente pedagógica, tornou-se referência teórica para setores da educação no Brasil.

A edificação da pedagogia histórico-crítica, no final dos anos de 1970, realizou-se em um momento de ruptura com o pensamento crítico-reprodutivista e instituição de uma teoria educacional que, consoante Saviani (2003a, p. 31), fosse capaz de "[...] superar tanto o poder ilusório (que caracteriza as teorias não-críticas ${ }^{3}$ ) como a impotência (decorrente 
das teorias crítico-reprodutivistas ${ }^{4}$ ), colocando nas mãos dos educadores uma arma de luta capaz de permitir-lhes o exercício de um poder real, ainda que limitado".

Observamos que, além da clara influência dos escritos de Marx e Gramsci, influenciaram nessa ruptura e edificação de uma concepção pedagógica crítica e propositiva, entre outros autores que procuravam abordar os problemas pedagógicos a partir das matrizes teóricas do materialismo histórico, o polonês Bogdan Suchodolsky (1907-1992), o italiano Mário Alighiero Manacorda (1914-) e o francês Georges Snyders (1917-). Saviani (2003b) menciona que, por parte de Georges Snyders, serviram de fontes à pedagogia histórico-crítica as obras Pedagogia progressista; Para onde vão as pedagogias não-diretivas; Escola, classe e luta de classes e A alegria na escola.

Ao tratar das ideias pedagógicas no Brasil, Saviani (2008) faz referência à criação de pedagogias contra-hegemônicas que nos anos de 1980, em busca de teorias que se contrapusessem à pedagogia oficial, tomaram fôlego. Dentre as propostas em construção, que a exemplo de Georges Snyders poderiam ser denominadas, em seu conjunto, de "pedagogias de esquerda" (SNYDERS, 1974), com toda a indeterminação que o termo traz, situa-se o processo de edificação da pedagogia histórico-crítica. Embora saibamos da existência de uma diversidade de propostas, as quais o autor em referência agrupa, de modo aproximado, em duas grandes tendências ou modalidades, ou seja, libertadora e libertária de um lado e, de outro, as de inspiração marxista, interessa-nos, neste momento, precisamente a segunda tendência descrita por Saviani (2008, p. 415), a qual

[...] aglutinou representantes cuja orientação teórica predominante se inspirava no marxismo, entendido, porém, com diferentes aproximações: uns mantinham como referência a visão liberal, interpretando o marxismo apenas pelo ângulo da crítica às desigualdades sociais e da busca de igualdade de acesso e permanência nas escolas organizadas com o mesmo padrão de qualidade; outros se empenhavam em compreender os fundamentos do materialismo histórico, buscando articular a educação com uma concepção que se contrapunha à visão liberal.

Além da pedagogia histórico-crítica, Saviani (2008, p. 418) expõe que, "no quadro da segunda tendência, situa-se a proposta formulada por José Carlos Libâneo, com o nome de 'pedagogia crítico-social dos conteúdos' e apresentada no livro Democratização da escola pública: a pedagogia crítico-social dos conteúdos, publicado em 1985 [...]". Informa-nos, ademais, que "a denominação 'pedagogia crítico-social dos conteúdos' inspira-se diretamente em Snyders [...]", e se sustenta na "[...] 'primazia dos conteúdos' como critério para distinguir as pedagogias entre si $[\ldots]$ ", conforme teoriza o próprio Georges Snyders.

Ainda que o autor de Democratização da escola pública: a pedagogia críticosocial dos conteúdos sinalize para o horizonte teórico do marxismo, uma vez que se inspira em Snyders, Saviani (2008, p. 418) adverte que, em tal obra, “[...] a mencionada referência teórica não chega a ser aprofundada, alimentando, antes, o objetivo da democratização da escola pública como sintomaticamente se expressa no próprio título do livro". De todo modo, o professor Libâneo, na referida obra, expõe as tendências pedagógicas segundo duas modalidades: 1) as liberais, abarcando a pedagogia tradicional, renovada progressista, renovada não diretiva e tecnicista; e, 2) as progressistas, reunindo a pedagogia libertadora, libertária e crítico-social dos conteúdos.

Para análise comparativa dessas diferentes tendências, o autor elege como critério os aspectos: papel da escola, conteúdos de ensino, métodos de ensino, relação professoraluno, pressupostos de aprendizagem e manifestações na prática escolar. 
No que se refere à pedagogia crítico-social dos conteúdos, situada entre as tendências de cunho progressista, as quais partem de uma análise crítica das realidades sociais, Libâneo (2008) explica que tal proposição pedagógica diferencia-se das outras pela ênfase que dá aos conteúdos no confronto com a realidade, pela síntese que propõe entre as pedagogias tradicional e renovada, pela valorização da ação pedagógica assentada na prática social concreta; e, ainda, no entendimento da escola como mediadora entre o individual e o social, na articulação entre transmissão dos conteúdos e sua assimilação ativa pelo aluno, com vistas à apropriação de um saber reelaborado criticamente.

Em sua proposição pedagógica, é possível encontrarmos termos e ideias que são próprios às formulações de Georges Snyders, confirmando a influência desse autor no trabalho de Libâneo (2008). É flagrante essa influência na referência que o autor brasileiro faz, por exemplo, aos conteúdos, os quais devem ser indissociáveis da realidade social, bem como devem ser aqueles constituídos em patrimônio comum da humanidade. Isso demanda que o professor intencione, por um lado, dar ao aluno acesso "[...] aos conteúdos, ligando-os com a experiência concreta dele - a continuidade; mas, de outro, de proporcionar elementos de análise crítica que ajudem o aluno a ultrapassar a experiência, os estereótipos, as pressões difusas da ideologia dominante - é a ruptura" (LIBÂNEO, 2008, p. 40, grifo do autor).

Apresentada a introdução e primeiras repercussões do pensamento de Georges Snyders no Brasil, elencamos outras referências à sua obra.

\section{Outras referências à obra de Georges Snyders}

Encontramos outras referências ao pensamento de Georges Snyders em publicações de autoria de Rossi (1981, 1982), Gadotti (1985, 1995) e Mizukami (1986).

Wagner Gonçalves Rossi faz referência à Georges Snyders nos volumes um e dois de seu livro intitulado Pedagogia do trabalho, os quais foram publicados em 1981 e 1982 respectivamente.

No volume um da obra, o objetivo do autor é levantar os fundamentos históricos da pedagogia do trabalho, a fim de preparar as condições para iniciar uma análise da configuração moderna dessa pedagogia. Ao escrever um sumário da contribuição de Rousseau (1712-1773), sobretudo no que toca à pedagogia do trabalho, Rossi (1981) faz referência à abrangente análise realizada por Georges Snyders acerca das propostas educativas rousseaunianas, presentes na obra La pédagogie en France aux XVIIe et XVIIIe siècles $^{5}$, cujo trabalho traz novos elementos para uma compreensão mais ampla da proposta pedagógica de Rousseau.

$\mathrm{O}$ autor recorre, também, à contribuição de Georges Snyders ao fazer referência à famosa experiência do educador Alexander Sutherland Neill (1883-1973), na escola de Summerhill (Inglaterra). Destaca, em um parágrafo, a análise crítica desenvolvida pelo pensador francês na obra Para onde vão as pedagogias não diretivas, no qual disseca a concepção de liberdade em Neill. E, ainda, referencia-o ao tratar da concepção de professor de Robert Owen (1771-1858). Rossi (1981, p. 91) afirma que as concepções de Owen e de Georges Snyders aproximam-se (tanto em Para onde vão as pedagogias não diretivas quanto em Escola, classe e luta de classes), no momento em que o segundo "[...] advoga a necessidade de o professor assumir seu papel diretivo concebido quase como uma vanguarda diretiva das massas $[\ldots]$ "..

Ao sumariar a contribuição de Francisco Ferrer Guardia (1859-1909) e destacar o tema da liberdade, uma vez mais Rossi (1981) recorre à Georges Snyders no sentido de 
deixar sinalizado que este contribui para um desenvolvimento mais amplo do tema em questão.

Já no volume dois da obra Pedagogia do trabalho, Rossi (1982) analisa os caminhos da educação socialista. Após discutir a contribuição de Moisey Mikhaylovich Pistrak (1888-1940), John Dewey (1859-1952), Antonio Gramsci (1891-1937), Paulo Freire (1921-1998), examina, no quinto capítulo, intitulado Outras contribuições importantes, algumas discussões de pensadores e educadores que considera concorrer para determinar os princípios da pedagogia do trabalho. Rossi (1982, p. 112) explica que, mesmo havendo outras contribuições que mereceriam ser apreciadas, faz a opção em "[...] incluir, pelo menos, uma curta referência àqueles que entre todos parecem mais significativos". Para tanto, procedeu "[...] à seleção de alguns educadores que constituem um grupo representativo de todo o conjunto de intelectuais cujos trabalhos têm sido considerados no processo de reconstrução de uma alternativa educacional revolucionária".

Apresentado seus critérios para selecionar alguns autores, entre muitos outros, Rossi (1982) examina brevemente as contribuições de Celestin Freinet (1896-1966), Anton Simionovich Makarenko (1888-1939), Maria Tereza Nidelcoff (1937-), assim como de Georges Snyders. Antes disso, porém, deixa sinalizado como sugestão que cada um dos trabalhos, ali examinados de modo breve, deveria ser, no futuro, estudado por outros pesquisadores, que poderão se incumbir de revelar a contribuição, em toda a sua extensão, oferecida por esses educadores para a composição da pedagogia do trabalho.

No tocante ao exame das contribuições de Georges Snyders, Rossi (1982) o faz em quatro páginas, nas quais estão indicadas, em nota de rodapé, somente duas obras do educador francês, que observamos servir de referência para a apresentação de suas contribuições. Trata-se dos livros Para onde vão as pedagogias não-diretivas? e Escola, classe e luta de classes.

Rossi (1982, p. 123) inicia a apresentação mencionando que o pensador francês

[...] desenvolveu uma análise profunda das chamadas pedagogias nãodiretivas e tentou revisar os principais críticos da educação capitalista em seu país no presente - Bourdieu e Passeron, Baudelot e Establet -, propondo ainda uma visão gramsciana da educação como antídoto a outras críticas, consideradas burguesas e alienadas, como as de Illich.

O autor brasileiro seleciona dois pontos das discussões do educador francês que considera particularmente importantes para a pedagogia. O primeiro trata-se da visão precisa de Georges Snyders acerca do caráter contraditório da escola, assinalando que esta “[...] não é nem apenas reprodutora, nem precipuamente revolucionária, mas local de confronto de interesses de classes antagônicas [...]" (ROSSI, 1982, p. 124). O segundo ponto, por sua vez, refere-se à caracterização das chamadas pedagogias não diretivas, em que revela o seu caráter conservador, uma vez que são entendidas como pedagogias legitimadoras da organização social tal como ela é.

Se, nesses dois pontos, Rossi (1982) aponta para uma particular contribuição de Georges Snyders, já no tocante à posição do professor na proposta snyderiana, o autor brasileiro mostra sua discordância. Na análise de Rossi (1982, p. 124), "a concepção de Snyders restaura a primazia do organizador sobre o povo, do partido sobre a massa operária", por isso considera que "[...] sua prescrição tende a depreciar a capacidade do estudante de trazer para a relação pedagógica uma contrapartida que o faça educador do educador". Em razão desse entendimento, aponta para o risco de se cair em um controle paternal e se resvalar no autoritarismo. Superar de modo dialético o autoritarismo e o 
espontaneísmo "[...] é exatamente um dos objetivos de uma educação autenticamente revolucionária".

Outro aspecto trazido por Rossi (1982, p. 125-126), no tópico destinado à Georges Snyders, refere-se ao uso do trabalho na educação. Afirma que "[...] Snyders distancia-se do ponto de vista tradicional do socialismo, colocando-se numa postura, até certo ponto, cética". Supõe que "[...] Snyders comete o engano de considerar como pedagogia do trabalho uma pedagogia que se basearia exclusivamente no trabalho [...]". Assinala, no entanto, que essa compreensão

[...] não corresponde à realidade, já que toda a proposta de uma pedagogia socialista do trabalho tem como elemento essencial a associação do trabalho produtivo à escolaridade tradicional, integrando-se educação e trabalho num único processo como meio de se superar a característica dicotômica da pedagogia burguesa, que separa e opõe teoria e prática, trabalho intelectual e trabalho manual (ROSSI, 1982, p. 126).

O autor brasileiro entende ser Georges Snyders limitado em relação à proposição de uma pedagogia baseada no trabalho, tema principal dos dois volumes de seu livro.

Observamos, neste ponto, ante a avaliação de Rossi (1982) sobre o educador francês, que Georges Snyders procura, em suas obras, dar respostas às questões de sua época, questões que, de algum modo, tocaram-no e o mobilizaram para discutir a respeito delas. É possível supor que a questão de interesse de Rossi (1982), qual seja, a pedagogia do trabalho, não tenha sido um problema fundamental para o educador francês, ao menos nas duas obras consultadas pelo autor brasileiro.

Moacir Gadotti é outro autor brasileiro que faz referência à Georges Snyders, por meio de seu livro História das idéias pedagógicas, no qual lhe dedica cinco páginas no último tópico da terceira parte do último capítulo do referido livro, intitulado Snyders: Enfim, uma escola não autoritária.

O autor brasileiro, após apresentar sumariamente Georges Snyders, bem como sinalizar dois pontos importantes de sua contribuição para a educação - a caracterização que faz das chamadas pedagogias não diretivas e a sua visão do caráter contraditório da escola, local de confronto de interesses de classes antagônicas -, deixa listado os títulos de quatro livros publicados pelo educador francês, quais sejam: Escola, classe e luta de classes; Pedagogia progressista; Não é fácil amar nossos fillhos; e, Para onde vão as pedagogias não-diretivas? (GADOTTI, 1995).

Em seguida, publica a transcrição de duas partes do livro A alegria na escola. Para isso, Gadotti (1995) abre aspas e, sob o título Alegria e alegrias culturais, transcreve todo o primeiro capítulo do livro de Snyders (1988), assim como transcreve, sob o título Uma escola não "totalitária", a última parte do mesmo livro. Após a transcrição, sem qualquer posicionamento ou diálogo com as ideias do autor francês, Gadotti (1995) fecha aspas e encerra o tópico apresentando como tarefa três perguntas para análise e reflexão do leitor. Além das cinco páginas dedicadas ao educador francês, nenhuma outra referência foi feita à Georges Snyders nesse material.

Localizamos outra referência no livro: Dialética do amor paterno, igualmente de autoria de Gadotti (1985), em que há menção à discussão de Georges Snyders desenvolvida no livro Não é fácil amar os nossos filhos, originalmente publicado na França em 1980.

Encontramos uma fugaz menção a um dos estudos de Georges Snyders no primeiro capítulo do livro Ensino: as abordagens do processo, de autoria de Mizukami (1986), no qual a autora trata da abordagem tradicional do processo de ensino. Em dois curtos 
parágrafos, a autora transcreve, de modo parcial e descontextualizado, aspectos da discussão que o educador francês realiza acerca do ensino tradicional na obra Pedagogia progressista.

Acerca dessa menção súbita e aligeirada, realizada pela autora brasileira, seria justo supor que, mesmo sendo referido com a melhor das intenções, trata-se de uma leitura desavisada do texto de Georges Snyders sobre a educação tradicional, isto é, fora do contexto de discussão do autor, não guardando sentido com suas ideias e ideais.

Além dos autores ora mencionados, encontramos, no cenário educacional brasileiro, algumas poucas pesquisas acadêmicas que versam sobre o pensamento snyderiano. Tratam-se das dissertações de mestrado de Sant'Ana Júnior (1993); Carvalho (1996); Ficagna (2004) e Castro (2004), bem como da tese de doutorado de Vieira (2011). Por se tratarem de trabalhos que se debruçam sobre a análise das ideias snyderianas, não abordaremos seus conteúdos, uma vez que o nosso foco de interesse, nesta oportunidade, incide sobre as apropriações da obra do autor em referência.

\section{Refluxo das publicações das obras de Georges Snyders em língua portuguesa}

Apresentadas as referências e menções que encontramos acerca do pensamento de Georges Snyders, feitas por autores brasileiros, sobretudo nos anos de 1980, destacamos que, apesar do fôlego dessa década, em que proposições de cunho progressista emergiram, na década de 1990, com a ascensão de governos de talhe neoliberal, houve um consequente refluxo dos movimentos progressistas e das propostas pedagógicas críticas (SAVIANI, 2008). Talvez por este motivo tenha havido um rápido apagamento, em nosso cenário educacional, das poucas discussões sobre as contribuições snyderianas.

Pode estar relacionada a essa inexpressiva influência do educador francês no Brasil a cessação, há mais de uma década, das publicações de suas obras em língua portuguesa. Com o fito de ilustrar esta observação, apresentamos, a seguir, um quadro com a totalidade das publicações de Georges Snyders.

\begin{tabular}{|c|c|c|}
\hline $\begin{array}{c}\text { Ano da } \\
\text { primeira } \\
\text { publicação } \\
\text { em francês }\end{array}$ & $\begin{array}{c}\text { Título da obra em francês e tradução para } \\
\text { o português }\end{array}$ & Outras informações \\
\hline 1964 & $\begin{array}{l}\text { La pédagogie en France aux XVIIe et XVIIIe } \\
\text { siècles } \\
\text { A pedagogia na França entre os séculos XVII } \\
\text { e XVIII }\end{array}$ & $\begin{array}{l}\text { Tese (459 páginas) } \\
\text { Sem publicação para língua } \\
\text { portuguesa }\end{array}$ \\
\hline 1965 & $\begin{array}{l}\text { La pédagogie en France aux XVIIe et XVIIIe } \\
\text { siècles } \\
\text { A pedagogia na França entre os séculos XVII } \\
\text { e XVIII }\end{array}$ & $\begin{array}{l}\text { Paris: Presses Universitaires de } \\
\text { France (459 páginas) } \\
\text { Tradução para língua alemã }\end{array}$ \\
\hline 1968 & $\begin{array}{l}\text { Le gôut musical en France aux } 17 \mathrm{e} \text { et } 18 \mathrm{e} \\
\text { siècles } \\
\text { O gosto musical na França entre os séculos } \\
\text { XVII e XVIII }\end{array}$ & $\begin{array}{l}\text { Paris: J. Vrien (192 páginas) } \\
\text { Sem tradução para língua } \\
\text { portuguesa }\end{array}$ \\
\hline 1971 & Pédagogie Progressiste & $\begin{array}{l}1971 \text { = primeira edição } \\
\text { Paris: Presses Universitaires de } \\
\text { France (189 páginas) }\end{array}$ \\
\hline
\end{tabular}




\begin{tabular}{|c|c|c|}
\hline & Pedagogia Progressista & $\begin{array}{l}1973 \text { = segunda edição revisada } \\
\text { e ampliada. } \\
\text { (275 páginas) } \\
1975 \text { = terceira edição } \\
\text { (275 páginas) } \\
\text { Tradução para língua espanhola, } \\
\text { italiana e portuguesa - Portugal } \\
\text { (1974) }\end{array}$ \\
\hline 1971 & $\begin{array}{l}\text { Traité des Sciences Pédagogiques: histoire de } \\
\text { la Pédagogie (organisé par Maurice Debesse } \\
\text { et Gaston Mialaret) } \\
\text { Chapitre intitulé: La pédagogie en France aux } \\
\text { XVIIe et XVIIIe siècles } \\
\text { Tratado de Ciências Pedagógicas: história da } \\
\text { pedagogia (organizado por Maurice Debesse e } \\
\text { Gaston Mialaret) } \\
\text { Capítulo intitulado: A pedagogia na França } \\
\text { entre os séculos XVII e XVIII }\end{array}$ & $\begin{array}{l}\text { Paris: Presses Universitaires de } \\
\text { France } \\
\text { Tradução para língua espanhola } \\
\text { e portuguesa (1974) }\end{array}$ \\
\hline 1973 & Para onde vão as pedagogies não-diretivas? & $\begin{array}{l}1973=\text { primeira edição } \\
\text { Paris: Presses Universitaire de } \\
\text { France ( } 324 \text { páginas) } \\
\begin{array}{l}1974=\text { segunda edição } \\
\text { páginas) }\end{array} \\
1975 \text { = terceira edição revista e } \\
\text { ampliada (378 páginas) } \\
\begin{array}{l}\text { Tradução para língua espanhola, } \\
\text { italiana, romena, grega e } \\
\text { portuguesa (1974) }\end{array}\end{array}$ \\
\hline 1976 & $\begin{array}{l}\text { École, classe et luttes de classes: une relecture } \\
\text { critique de Baudelot-Establet, Bourdieu- } \\
\text { Passeron et Illich } \\
\text { Escola, classe e luta de classes: uma releitura } \\
\text { crítica de Baudelot-Establet, Bourdieu- } \\
\text { Passeron e Illich }\end{array}$ & $\begin{array}{l}\text { 1976 = primeira edição } \\
\text { Paris: Presses Universitaires de } \\
\text { France ( } 377 \text { páginas) } \\
1982 \text { = segunda edição } \\
\begin{array}{l}\text { Tradução para língua espanhola, } \\
\text { italiana, holandesa, grega e } \\
\text { portuguesa (1977) }\end{array}\end{array}$ \\
\hline 1979 & $\begin{array}{l}\text { La actitud de izquierda en Pedagogía } \\
\text { A atitude de esquerda em Pedagogia }\end{array}$ & $\begin{array}{l}\text { México: Ediciones de Cultura } \\
\text { Popular (64 páginas) } \\
\text { Sem tradução para língua } \\
\text { francesa e portuguesa }\end{array}$ \\
\hline
\end{tabular}




\begin{tabular}{|c|c|c|}
\hline 1980 & Il n'est pas facile d'aimer ses enfants & $\begin{array}{l}\text { 1980 = primeira edição } \\
\text { Paris: Presses Universitaire de } \\
\text { France ( } 291 \text { páginas) } \\
1982 \text { = segunda edição ampliada } \\
\text { (304 páginas) } \\
\text { Tradução para língua espanhola, } \\
\text { holandesa, japonesa e portuguesa } \\
\text { (1984) }\end{array}$ \\
\hline 1984 & $\begin{array}{l}\text { Correntes actuais da Pedagogia (organisé par } \\
\text { Georges Snyders, Antoine Léon et Rui } \\
\text { Grácio) } \\
\text { Capítulo intitulado: Pedagogias não-directivas } \\
\text { (da página } 15 \text { a 38) }\end{array}$ & $\begin{array}{l}\text { Lisboa: Livros Horizonte. } \\
\text { Publicação em língua portuguesa } \\
\text { e sem tradução para língua } \\
\text { francesa }\end{array}$ \\
\hline 1986 & $\begin{array}{l}\text { La joie à l'école } \\
\text { A alegria na escola }\end{array}$ & $\begin{array}{l}\text { Paris: Presses Universitaires de } \\
\text { France (329 páginas) } \\
\text { Tradução para língua espanhola } \\
\text { e portuguesa (1988) }\end{array}$ \\
\hline 1989 & $\begin{array}{l}\text { L'école peut-elle enseigner les joies de la } \\
\text { musique? } \\
\text { A escola pode ensinar as alegrias da música? }\end{array}$ & $\begin{array}{l}\text { Issy-les-Moulineaux: Ed. EAP. } \\
\text { (130 páginas) } \\
\text { Tradução para língua portuguesa } \\
\text { (1992) }\end{array}$ \\
\hline 1991 & $\begin{array}{l}\text { Alunos felizes: reflexão sobre a alegria na } \\
\text { escola a partir de textos literários }\end{array}$ & $\begin{array}{l}\text { 1991 = primeira edição } \\
\text { Issy-les-Moulineaux: EAP (160 } \\
\text { páginas) } \\
1999=\text { nova edição } \\
\text { ampliada/debate com Jean } \\
\text { Houssaye } \\
\text { Paris; Montreal (Québec): } \\
\text { L’Harmattan (160 páginas) } \\
\begin{array}{l}\text { Tradução para língua portuguesa } \\
\text { (1993) }\end{array}\end{array}$ \\
\hline 1994 & $\begin{array}{l}\text { Heureux à l'université: étude à partir de } \\
\text { quelques biographies } \\
\text { Feliz na universidade: estudo a partir de } \\
\text { algumas biografias }\end{array}$ & $\begin{array}{l}\text { Paris: Nathan Pédagogie (203 } \\
\text { páginas) } \\
\text { Tradução para língua portuguesa } \\
\text { (1995) }\end{array}$ \\
\hline 1996 & $\begin{array}{l}\text { Y a-t-il une vie après l'école: les études après } \\
\text { les études, quelles joies? }\end{array}$ & Paris: ESF éditeur (140 páginas) \\
\hline
\end{tabular}




\begin{tabular}{|c|c|c|}
\hline & $\begin{array}{l}\text { Existe uma vida após a escola: os estudos } \\
\text { após os estudos, quais alegrías? }\end{array}$ & $\begin{array}{l}\text { Sem tradução para língua } \\
\text { portuguesa }\end{array}$ \\
\hline 1998 & $\begin{array}{l}\text { Marx au regard de Jaurès: Jaurès et nous, } \\
\text { Jaurès et moi } \\
\text { Marx ao olhar de Jaurès: Jaurès e nós, Jaurès e } \\
\text { eu }\end{array}$ & $\begin{array}{l}\text { Vigneux (France): Ed. Matrice } \\
\text { (48 páginas). } \\
\text { Sem tradução para língua } \\
\text { portuguesa }\end{array}$ \\
\hline 1999 & $\begin{array}{l}\text { La musique comme joie à l'école } \\
\text { A música como alegria na escola }\end{array}$ & $\begin{array}{l}\text { Paris; Montreal (Québec): } \\
\text { L’Harmattan (214 páginas) } \\
\text { Sem tradução para língua } \\
\text { portuguesa }\end{array}$ \\
\hline 2001 & $\begin{array}{l}\text { L'école comme vie, la vie en tant qu'école } \\
\text { A escola como a vida, a vida como uma } \\
\text { escola }\end{array}$ & $\begin{array}{l}\begin{array}{l}\text { Vigneux: Édition Matrice (61 } \\
\text { pages) }\end{array} \\
\text { Sem tradução para língua } \\
\text { portuguesa }\end{array}$ \\
\hline 2002 & $\begin{array}{l}\text { De la culture, des chefs-d'oeuvre, et des } \\
\text { hommes, à l'école } \\
\text { Da cultura, das obras-primas e dos homens, na } \\
\text { escola }\end{array}$ & $\begin{array}{l}\text { Vigneux: Édition Matrice (70 } \\
\text { páginas) } \\
\text { Sem tradução para língua } \\
\text { portuguesa }\end{array}$ \\
\hline 2004 & $\begin{array}{l}\text { Toujours à gauche: propos et parfois échanges } \\
\text { avec Jacques Ardoino } \\
\text { Sempre à esquerda: propósitos e às vezes } \\
\text { trocas com Jacques Ardoino }\end{array}$ & $\begin{array}{l}\text { Vigneux: Édition Matrice (301 } \\
\text { páginas) } \\
\text { Coleção de textos publicados } \\
\text { entre } 1998 \text { e } 2004 \\
\text { Sem tradução para língua } \\
\text { portuguesa }\end{array}$ \\
\hline 2008 & $\begin{array}{l}\text { J'ai voulu qu'apprendre soit une joie } \\
\text { Quero que aprender seja uma alegria }\end{array}$ & $\begin{array}{l}\text { Paris: Éditions Syllepse (267 } \\
\text { páginas) } \\
\text { Sem tradução para língua } \\
\text { portuguesa }\end{array}$ \\
\hline
\end{tabular}

Quadro 1 - Livros publicados por Georges Snyders.

Fonte: Obras de autoria de Georges Snyders.

Ao recorrermos à cronologia das publicações das primeiras edições francesas dos livros de Georges Snyders, a fim de traçar o itinerário de suas obras, detectamos que as publicações do autor datadas de meados da década de 1990 não mais tiveram traduções para a língua portuguesa, seja de Portugal seja do Brasil.

A cessação das publicações em português dos livros do autor em referência, a partir de meados dos anos de 1990, possivelmente concorreu para dificultar a difusão de suas ideias. Esse fato pode estar relacionado, entre outras coisas, com a ascensão e difusão de 
outras perspectivas teóricas no cenário educacional brasileiro. Apresentadas como inovadoras, as novas perspectivas revelaram-se, em geral, opostas ao materialismo histórico, aporte teórico das produções snyderianas.

Ademais, entendemos, tal como Saviani (2008), que concorreu para o refluxo das proposições de natureza progressista, como as contidas nas obras de Georges Snyders, a reconfiguração do cenário educacional brasileiro, promovida pela ascensão de políticas neoliberais.

É no cerne desse contexto que precisamos avaliar sobre a descontinuidade de publicações, em língua portuguesa, das obras de Georges Snyders. Em nosso entendimento, ao incorporar as novas tendências em ascensão, as editoras também contribuem para o estabelecimento de determinadas leituras em detrimento de outras. Certamente, não estão isentas as razões comerciais e ideológicas para cessação das publicações das obras de Snyders em língua portuguesa.

\section{Considerações finais}

Mediante o exposto acerca da introdução, apropriações e refluxo da obra de Georges Snyders no cenário educacional brasileiro, consideramos que embora sua obra pedagógica seja uma referência que aportou, pela primeira vez, no Brasil, nos idos de 1970, portanto em outro contexto histórico e educacional, o contato com o seu pensamento educacional seja, ainda hoje, inspirador, sobretudo se consideramos que tal pensamento pedagógico inspirou, outrora, a construção da pedagogia histórico-crítica.

Ademais, sobre sua influência em território nacional, notamos que, em que pese a constatação do refluxo da publicação de suas obras em língua portuguesa, de um modo geral, as proposições pedagógicas críticas ainda são foco de interesse de parcela dos educadores brasileiros. Essa observação respalda-se na grande acolhida das obras de Dermeval Saviani (exemplo disso é o livro Escola e democracia, que se encontrava em sua $42^{\mathrm{a}}$ edição no ano de 2012 e o livro Pedagogia histórico-crítica: primeiras aproximações, em sua $11^{a}$ edição igualmente no ano de 2012) e José Carlos Libâneo (seu livro Democratização da escola pública: a pedagogia crítico social dos conteúdos encontrava-se em sua $22^{a}$ edição no ano de 2008).

No tocante às apropriações de sua obra, observamos que suas ideias nem sempre foram estudadas em profundidade, bem como as referências feitas por aqui se inclinaram, muitas vezes, à parcialidade.

A respeito dessa parcialidade, entendemos que a prática de pinçar de uma obra aquilo que melhor convém ao trabalho realizado ou, então, privilegiar alguns aspectos em detrimento de outros, sem aprofundá-los, fragmenta a obra do autor consultado, neutralizando-a de seu real significado. Daí afirmarmos a importância de se estudar o conjunto da obra de um autor e o próprio autor.

Por fim, consideramos que sua obra ainda hoje seja fértil posto que seu ideário pedagógico foi concebido fundamentado em perspectiva crítica e dialética. Sobre a abordagem dialética, notamos que, pela sua lógica intrínseca, esta não permite simples transferência de conclusões de um contexto para outro sem se processar as devidas adequações histórico-teóricas. Nesse sentido, não esperamos encontrar nas obras de Georges Snyders soluções prontas para problemas hodiernos. Na realidade, entendemos que o avanço teórico por ele produzido pode nos dar base para a exploração de questões relativas ao terreno da educação escolar e da pedagogia como, por exemplo, a questão do papel do aluno, do professor, da cultura, formação, valorização do ensino, inovações pedagógicas, entre outros temas, potencializando nossa compreensão sobre os mesmos. 


\section{Referências}

CARVALHO, R. M. B. de. Georges Snyders: em busca da alegria na escola. 1996. 149 f. Dissertação (Mestrado em Educação)-Pontifícia Universidade Católica de São Paulo, São Paulo, 1996.

CASTRO, A. H. I. de. Educação, cultura e poder na obra de Georges Snyders: rastros e rumos da alegria na escola. 2004. 190 f. Dissertação (Mestrado em Educação Escolar)Faculdade de Ciências e Letras, Universidade Estadual Paulista, Araraquara, 2004.

DUARTE, N. Educação escolar, teoria do cotidiano e a escola de Vigotski. 3. ed. rev. e ampl. Campinas, SP: Autores Associados, 2001a.

Vigotski e o “aprender a aprender": crítica às apropriações neoliberais e pósmodernas da teoria vigotskiana. 2. ed. rev. e ampl. Campinas, SP: Autores Associados, $2001 b$.

Sociedade do conhecimento ou sociedade das ilusões? Quatro ensaios críticodialéticos em filosofia da educação. Campinas, SP: Autores Associados, 2003.

FICAGNA, A. V. O. O pensamento político-pedagógico de Georges Snyders. 2004. 119 f. Dissertação (Mestrado em Educação)-Universidade de Passo Fundo, Passo Fundo, 2004.

GADOTTI, M. Dialética do amor paterno. São Paulo: Cortez, 1985.

História das idéias pedagógicas. 3. ed. São Paulo: Ática, 1995.

LIBÂNEO, J. C. Democratização da escola pública: a pedagogia crítico-social dos conteúdos. 22. ed. São Paulo: Loyola, 2008.

MIZUKAMI, M. G. N. Ensino: as abordagens do processo. São Paulo: EPU, 1986.

MORAES, M. C. M. de. Recuo da teoria: dilemas na pesquisa em educação. Revista Portuguesa de Educação, Braga, v. 14, n. 1, p.7-25, 2001.

ROSSI, W. G. Pedagogia do trabalho: raízes da educação socialista. São Paulo: Moraes, 1981, v. 1. 1982, v. 2.

Pedagogia do trabalho: caminhos da educação socialista. São Paulo: Moraes,

SANT'ANA JÚNIOR, H. A. O anjo, a tempestade e a escola: elementos para a compreensão da relação entre a noção de progresso, marxismo e pedagogia progressista. 1993. 167 f. Dissertação (Mestrado em Educação Escolar Brasileira)-Universidade Federal de Goiás, Goiânia, 1993.

SAVIANI, D. Georges Snyders ou a pedagogia marxista da alegria. Campinas, SP, 1988. Texto digitado.

Escola e democracia: teoria da educação, curvatura da vara, onze teses sobre a educação política. 36. ed. Campinas, SP: Autores Associados, 2003a.

Pedagogia histórico-crítica: primeiras aproximações. 8. ed. Campinas, SP:

Autores Associados, 2003b.

. História das idéias pedagógicas no Brasil. 2. ed. Campinas, SP: Autores

Associados, 2008.

SNYDERS, G. Pedagogia progressista. Coimbra: Almedina, 1974.

A alegria na escola. São Paulo: Manole, 1988.

Revista HISTEDBR On-line, Campinas, $n^{o}$ 59, p.285-298, out2014-ISSN: 1676-2584 297 
VIEIRA, R. A. Contribuições do pensamento pedagógico de Georges Snyders para a abordagem do antipreconceito. 2011, 255f. Tese (Doutorado)-Programa de PósGraduação em Educação, Universidade Estadual de Maringá, Maringá, 2011.

\section{Notas}

${ }^{1}$ Universidade Estadual de Maringá realvieira@gmail.com

2 Trata-se de pesquisa de doutorado, de nossa autoria, materializada na tese intitulada Contribuições do posicionamento pedagógico de Georges Snyders para a abordagem do antipreconceito, defendida no ano de 2011, junto ao Programa de Pós-Graduação em Educação da Universidade Estadual de Maringá.

${ }^{3} \mathrm{Na}$ definição de Saviani (2003a), as teorias não críticas da educação são compostas pela Pedagogia Tradicional, Pedagogia Nova e a Pedagogia Tecnicista.

${ }^{4}$ Conforme Saviani (2003a), as teorias crítico-reprodutivistas expressam-se na teoria do sistema de ensino como violência simbólica, formulada por Pierre Bourdieu (1930-2002) e Jean Claude Passeron (1930-); na teoria da escola como aparelho ideológico de Estado, elaborada por Louis Althusser (1918-1990); na teoria da escola dualista de autoria de Christian Baudelot (1938-) e Roger Establet (1938-). Saviani (2003a, p. 2930) assim sintetiza tais teorizações: "enquanto as teorias não-criticas pretendem ingenuamente resolver o problema da marginalidade por meio da escola sem jamais conseguir êxito, as teorias crítico-reprodutivistas explicam a razão do suposto fracasso. Segundo a concepção crítico-reprodutivista, o aparente fracasso é, na verdade, o êxito da escola; aquilo que se julga ser uma disfunção é, antes, a função própria da escola. Com efeito, sendo um instrumento de reprodução das relações de produção, a escola na sociedade capitalista necessariamente reproduz a dominação e exploração".

${ }^{5}$ A pedagogia na França entre os séculos XVII e XVIII. 